\title{
Más allá de mí: cuidarme para proteger mi hijo. Experiencias de mujeres gestantes con VIH/SIDA
}

\author{
Beyond me: take care for the protection of my son. \\ Experiences of pregnant women with HIV/ AIDS
}

Yurian Lida Rubiano Mesa ${ }^{1}$, Rosa Yolanda Munevar Torres ${ }^{1}, B^{2}$ runhilde Goethe Sánchez ${ }^{1}$

Forma de citar: Rubiano Mesa YL, Munevar Torres RY, Goethe Sánchez B. Más allá de mí: cuidarme para proteger mi hijo. Experiencias de mujeres gestantes con VIH/SIDA. Rev Univ Ind Santander Salud. 2016; 48(3): $353-363$. DOI: http://dx.doi.org/10.18273/revsal.v48n3-2016009 (c) (1) €

\section{RESUMEN}

Introducción: En el mundo más de 33 millones de personas viven con VIH/SIDA y casi la mitad de ellas son mujeres en edad reproductiva, pero poco se conoce cómo viven las mujeres una gestación con diagnóstico de seropositividad. Objetivo: Comprender el significado de vivir con VIH/SIDA durante la gestación, de un grupo de mujeres atendidas en dos Empresas Sociales del Estado (ESE) de la ciudad de Bogotá, entre 2013 y 2014. Metodología: Estudio cualitativo, fenomenológico interpretativo, con participación de diez mujeres en puerperio lejano que viven con VIH/SIDA, seleccionadas según criterios de pertinencia y adecuación. La muestra se definió por saturación teórica y la recolección de datos mediante entrevistas a profundidad. El análisis siguió la técnica de Colaizzi. Resultados: El significado de vivir con VIH/SIDA durante la gestación, para el grupo de mujeres participantes, fue "Vivir con VIH/SIDA en la gestación: una experiencia por la protección del hijo" como tema central, sustentado por tres categorías: "Entre la noticia y la aceptación", "Proteger al hijo" y "Confiar en alguien algo ayuda". Conclusiones: La gestación con diagnóstico de VIH/SIDA es un fenómeno complejo, que traspasa aspectos biológicos y farmacológicos para demandar cuidados interdisciplinarios sociales, sicológicos, espirituales y familiares, pues el centro de atención es el hijo en gestación y los ya existentes; desbordando la capacidad del sistema de salud. Por tanto, se necesita avanzar en la formación del personal de salud especialmente del equipo de enfermería, en estrategias innovadoras de acompañamiento, orientación y apoyo a las gestantes y sus familias quienes viven este evento.

Palabras clave: VIH, Síndrome de inmunodeficiencia adquirida, mujeres embarazadas, Acontecimientos que cambian la vida, investigación cualitativa.

\begin{abstract}
Introduction: In the world, more than 33 millions of people currently live with HIV/AIDS; nearly half of them are women of reproductive age. Nonetheless, little is known about of how women live with a diagnosis of

1. Universidad Nacional de Colombia. Bogotá DC, colombia

Correspondencia: Yurian Lida Rubiano Mesa. Dirección: Cra 58C 152-66 Colina Campestre Cantobrica 1. Correo electrónico: ylrubianom@ unal.edu.co. Teléfono: 3165000 ext. 17081
\end{abstract}


seropositivity. Objetives: To understand the meaning of living with HIV/AIDS during pregnancy in a group of women who were treated in two State Social Enterprises (ESE) in Bogotá, between 2013-2014. Methodology: A qualitative research based on interpretative phenomenological approach, with the participation of ten women who were in postpartum period living with HIV/AIDS. They were selected with the criteria of relevance and adequacy. The sample was defined by theoretical saturation and for the collection of data was used were in depth interviews. For data analysis was used the Colaizzi's method. Results: The meaning of living with HIV/AIDS during pregnancy, for women group who participated was: "Live with HIV/AIDS on the pregnancy: An experience for the protection the son". This central topic was supported by three categories: between the notice and the acceptance, protecting the son and trusting someone help. Conclusions: Pregnancies developed with HIV/AIDS diagnosis is a complex phenomenon that, beyond of biological and pharmacological aspects, demands social, psychological, spiritual and family care, as the newborn and the other children represent the main attention focus for pregnant women. Also, these events strain an overloaded our health system capacity. Therefore, further progress is needed for health staff training, especially for nurses, on support innovative strategies, guidance and support to pregnant women with HIV/ AIDS and their families.

Keywords: HIV, Acquired Immunodeficiency Syndrome, Pregnant Women, Life Change Events, Qualitative Research.

\section{INTRODUCCIÓN}

Según el informe de ONUSIDA durante el año 2014 en el mundo 36.9 millones de personas vivían con VIH, dos millones fueron registrados como casos nuevos, 1.2 millones murieron por enfermedades relacionadas con el SIDA y 13.6 millones de personas tenían acceso al tratamiento antirretroviral que corresponde a $40 \%$ de los afectados, frente a 15.8 millones en tratamiento a junio del 2015, por tanto los resultados son mayor sobrevida y mejor salud ${ }^{1,2}$.

En el mundo, la proporción de mujeres que viven con $\mathrm{VIH} / \mathrm{SIDA}$ se ha mantenido estable en un 50\%, aunque este grupo poblacional continúa siendo el más afectado en África subsahariana (59\%) y el Caribe $(53 \%)^{3}$. En Colombia, para el año 2012 se reportaron un total de 8.196 nuevos casos, de los cuales el 27,8\% fueron mujeres (2.282) que se concentran entre los 25 y 34 años de edad ${ }^{4}$.

En el año 2010 en Colombia se tamizaron 366.237 gestantes y de éstas, $476(0.13 \%)$ fueron casos nuevos para VIH/SIDA, mejorando el registro respecto al año 2003 en el cual se tamizaron 33.751 casos y de estos 82 fueron casos nuevos $(0.24 \%)$. Así mismo, la prevalencia en gestantes no es mayor a $1 \%$. Lo anterior es el reflejo del efecto de las políticas del país que apuntan a mejorar el registro y notificación de casos, ampliar la cobertura, promover el acceso al tratamiento profiláctico, asesorías y pruebas voluntarias con oferta masiva a las gestantes; garantizar la continuidad del suministro de retrovirales posterior al nacimiento, seguimiento médico al neonato, suministro de fórmulas lácteas durante los primeros seis meses de vida ante la supresión de la lactancia materna, exámenes de laboratorio para identificar tempranamente la infección en el neonato, seguimiento y disminución de las barreras administrativas para acceder a los servicios; en un esfuerzo por identificar oportunamente los casos de seropositividad materna y limitar la transmisión de la enfermedad por vía vertical al neonato ${ }^{3}$.

A pesar del incremento de la epidemia entre las mujeres, la exposición al riesgo y las condiciones de vulnerabilidad, y de las estrategias definidas para prevenir la enfermedad y la transmisión madre-hijo, la literatura registra pocos estudios en Latinoamérica y en Colombia que permitan vislumbrar respuestas a la amplia gama de requerimientos de cuidado que van más allá de lo físico y farmacológico y que las gestantes expresan en sus experiencias vividas cuando son diagnosticadas con VIH/SIDA. De manera que el diseño de políticas, planes y estrategias de prevención para mejorar las condiciones de salud de las mujeres durante su gestación, requiere tener en cuenta que la eficacia y efectividad de cualquier actividad que se emprenda, depende de las perspectivas que ellas y sus familias tienen del problema ${ }^{5}$. Frente a esto, en Colombia la información disponible sobre lo que piensan y sienten las embarazadas acerca de los riesgos durante la gestación, el control prenatal, la atención recibida o el parto hospitalario, entre otros; es escasa y poco visible 6 .

Por la situación descrita anteriormente, el objetivo de este estudio fue comprender el significado de vivir con VIH/SIDA durante la gestación de un grupo de mujeres atendidas en dos Empresas Sociales del Estado (ESE) de la ciudad de Bogotá. 


\section{MATERIALES Y MÉTODOS}

Estudio cualitativo para abordar las realidades subjetivas e intersubjetivas como objetos legítimos de conocimiento e intentar comprender desde la interioridad de los actores sociales las lógicas de pensamiento que guían las acciones sociales, rescatando su diversidad y particularidad, haciendo énfasis en la valoración de lo subjetivo, vivencial e interacción entre los sujetos de investigación; y desde lo cotidiano buscar comprender las relaciones, visiones, temporalidades, sentidos y significados ${ }^{7}$.

El enfoque es fenomenológico basado en la filosofía ontológica de Heidegger ${ }^{8}$ y "Cómo método investigativo está interesado en entender los fenómenos en sus propios términos, para lo cual se deben descubrir y entender los significados, hábitos y prácticas del ser humano" ". Para Wojnar ${ }^{10}$, el objetivo de la investigación fenomenológica es identificar los significados de los participantes a partir de la combinación de tres elementos: comprensión del investigador acerca del fenómeno, información generada por el participante y datos obtenidos de otras fuentes pertinentes.

El foco de la investigación fenomenológica son las experiencias de la persona en relación con un fenómeno. En este sentido, la fenomenología asume que las experiencias dan sentido a la percepción de cada persona sobre un fenómeno particular; siendo su objetivo la descripción de la experiencia y de las percepciones que ella expresa. Lo anterior propone la representación de la estructura total de la experiencia vivida, incluyendo el significado que estas experiencias tienen para los individuos que en ellas participan, preocupándose de la compresión y no de la explicación'. Por lo anterior, este diseño es apropiado para la compresión del significado para las mujeres de vivir con VIH/SIDA durante la gestación.

El estudio se realizó durante los años 2013 y 2014, con participación voluntaria de diez mujeres mayores de 18 años, en periodo de puerperio y diagnosticadas con VHI/SIDA durante la gestación y residentes en Bogotá. Fueron atendidas en dos instituciones públicas (ESE) de III nivel de atención de la ciudad de Bogotá (Colombia) donde se realizó el estudio. No se incluyeron mujeres con alteraciones de comportamiento evidente, que no asistieron a control prenatal y en condiciones clínicas críticas o de su hijo que no les permitieran narrar sus experiencias.

Se utilizó un muestreo a conveniencia, y en la selección de las participantes se tomó en cuenta los criterios de pertinencia porque fueron mujeres gestantes que aportaron la mayor cantidad de datos relacionados con el fenómeno de estudio; y adecuación porque éstos fueron suficientes para desarrollar una completa y rica descripción del fenómeno cuando la etapa de saturación se alcanzó es decir no hubo nuevos datos ${ }^{11,12}$.

La recolección de datos se realizó mediante entrevistas a profundidad, para comprender el significado de la experiencia de una mujer en gestación y que vive con VIH/ SIDA $^{13,14}$. Se partió de la pregunta generadora: ¿Cómo vivió usted su embarazo? Cada entrevista duró entre una $\mathrm{y}$ una hora treinta minutos aproximadamente, y fueron grabadas en audio y transcritas íntegramente por las investigadoras. Además, se utilizó un diario de campo en el cual se registraron los acontecimientos y observaciones significativas durante la recolección y análisis de los datos. En el desarrollo de las entrevistas algunas de las participantes presentaron episodios de llanto, por lo cual fue necesario suspenderlas, permitiéndose la expresión de sentimientos, acompañándole hasta que se sintieran mejor. La sesión se reanudó cuando estuvieron dispuestas y ella así lo expresaron.

Los datos se analizaron siguiendo la técnica de análisis fenomenológico de Colaizzi (1978) ${ }^{10}$ (Tabla 1). Los resultados fueron socializados con tres de las participantes, previo a concluir el análisis de los mismos.

Se tuvieron en cuenta los criterios de rigor metodológico de credibilidad, auditabilidad y transferibilidad propuestos por Lincoln y Guba (citados por Vásquez, et al. $)^{15}$.

Tabla 1. Resumen del método de análisis Colaizzi (1978).

\begin{tabular}{cl}
\hline $\begin{array}{c}\text { PASOS DEL } \\
\text { ANÁLISIS }\end{array}$ & \multicolumn{1}{c}{ PROPÓSISTOS } \\
\hline PASO 1 & $\begin{array}{l}\text { Adquirir sensación general de la experiencia. } \\
\text { Generar información directamente pertinente } \\
\text { al fenómeno estudiado. }\end{array}$ \\
PASO & $\begin{array}{l}\text { Iluminar significados escondidos en varios } \\
\text { contextos del fenómeno. }\end{array}$ \\
PASO 4 & $\begin{array}{l}\text { Identificar experiencias comunes a todos los } \\
\text { informantes. }\end{array}$ \\
PASO 5 & $\begin{array}{l}\text { Generar un prototipo de un modelo teórico. } \\
\text { PASO } 6\end{array}$ \\
Validar los hallazgos. \\
PASO 7 & $\begin{array}{l}\text { Presentar un modelo teórico que refleje } \\
\text { comprensivamente las características } \\
\text { universales del fenómeno. }\end{array}$ \\
\hline
\end{tabular}

Fuente: Wojnar y Swanson, 2007. 


\section{RESULTADOS}

El estudio se realizó en dos ESE de tercer nivel de Bogotá ${ }^{1}$ que son centros de referencia para la atención de gestantes con VIH/SIDA en la ciudad. Participaron diez mujeres, cuatro de ellas atendidas en el Hospital B y seis en el Hospital T, todas pertenecientes al régimen subsidiado. La edad promedio de las participantes fue 25 años (rango 1835 años), la mitad eran bachilleres y nueve de ellas vivían en unión libre con sus parejas.

Del total de participantes, ocho fueron diagnosticados entre la semana 12 y 24 de gestación, y dos entre la semana 28 y 34 respectivamente. Todas las gestaciones terminaron por vía cesárea, cuatro nacimientos fueron prematuras ( 32 y 34 semanas) y seis a término. Todas las mujeres tenían instaurado tratamiento retroviral y expresaron seguirlo.

\section{CATEGORÍAS Y SUB-CATEGORÍAS EMERGENTES}

El tema emergente en el estudio fue "Vivir con VIH/ SIDA en la gestación: una experiencia por la protección del hijo" se construyó a partir de tres categorías y subcategorías que se describen a continuación.

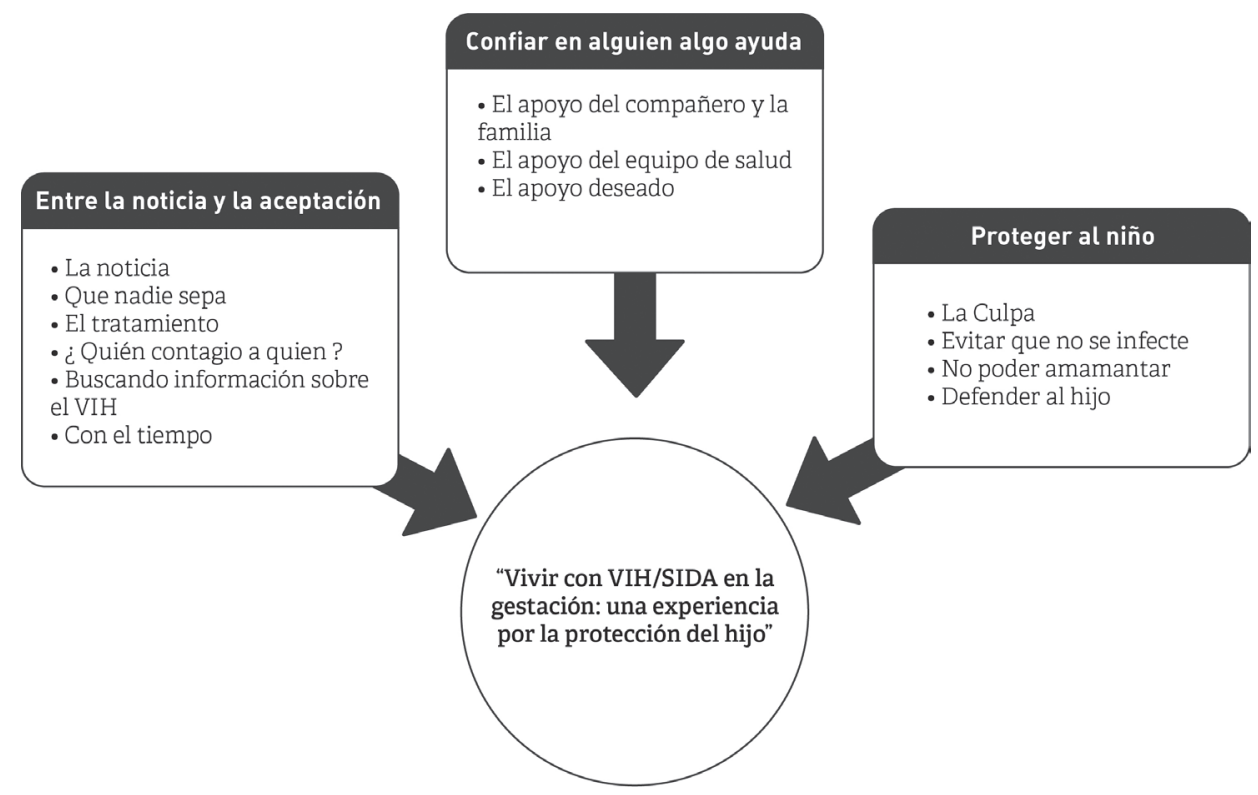

Figura 1. Modelo propuesto para comprender las vivencias de la gestación de mujeres con VIH/SIDA.

\section{La noticia y la aceptación}

La noticia. Las mujeres que participaron en el estudio, desde el momento en que recibieron la noticia del diagnóstico de $\mathrm{VIH}$, experimentaron una gran carga emocional, sintieron el peso del entorno proveniente del personal de salud, la pareja sentimental, familiar y social. Recibir la noticia les implicó una larga e interminable espera, y pasar por diferentes controles y procedimientos como: cumplimiento de citas, nuevos laboratorios y pruebas confirmatorias, urgencia en la obtención de resultados, entre otros. Por lo general son las enfermeras las encargadas de informarles: "(...) No... lo que yo le voy a decir no es fácil: "su prueba de VIH le salió positiva". Así me dijo [llora], yo me quedé mirándola y le decía:

${ }^{\mathrm{I}}$ Por razones de la confidencialidad y privacidad de las participantes, los hospitales se denominaron como B y $\mathrm{T}$.
¿Qué, qué? Y ella repetía: "su prueba le salió positiva”. P3HTE1F1 Así, el momento de recibir la noticia marca el inicio de una vivencia compleja: estar en embarazo y ser portador del VIH: “(...) lo único que pensé fue en mi hija, porque ella es una niña, apenas va a empezar la vida... [Silencio]". P5HTE1F3

Para una mujer gestante ser portadora del VIH es una noticia impactante que expresan con llanto, silencios prolongados y expresiones: "Uno se siente como morir”, "La vida se le va”, “ ¿Por qué Yo?”, las cuales dan cuentan del temor y la angustia que provoca tener que enfrentarse a experiencias desconocidas, que incluyen contemplar la probabilidad de morir. También, la noticia las confronta con sus "propias historias y sus relaciones interpersonales". A partir de este momento, aparecen nuevas inquietudes, una de ellas es quién puede o no saber; dando paso a la siguiente sub-categoría. 
Que nadie sepa. Contar que son portadoras de VIH o no, a sus allegados se convierte en un dilema al que se enfrentan las mujeres. Mantener en secreto su seropositividad se plantea como una estrategia para proteger su existencia y la de su hijo. Esta decisión les ocasiona gran preocupación, angustia y miedo, especialmente por la posible reacción negativa del compañero sentimental. En igual sentido, contar la noticia fue una causa de rechazo por familiares cercanos y por otras personas fuera del entorno familiar. Ella dice: “(...) mi mamá apenas se enteró del embarazo me dijo que abortara, no me hablaba, me trataba mal y cuando le conté eso, peor. Hubo un tiempo que yo me sentía rechazada, porque ella, por ejemplo, cuando yo le ofrecía algo de lo que yo comía, no aceptada, como si le diera asco. Me sentía rechazada, como si yo fuera diferente a ella." P3HTE1F23.

Contar o no la noticia es el primer reto que viven, y a este siguen otros como iniciar y continuar el tratamiento, así lo describen:

El tratamiento. Es un evento nuevo asociado al diagnóstico que implica tomar medicamentos retrovirales, asistir a consultas con infectología, ginecología, trabajo social, nutrición, psicología e incluso psiquiatría, tomar muestras para laboratorio como un imperativo que deben cumplir, pues no son considerados opcionales. Sin embargo, la adherencia al tratamiento está determinada por la supervivencia de ella y sus hijos y la necesidad de disminuir el riesgo de transmisión vertical del virus a su hijo en gestación. Ella comenta: “(...) si no los tomo (los medicamentos) me voy a enfermar, me voy a sentir mal, las pastillas son como nuestra salvación, pero le ruego a Dios que mi hijo no tenga que tomar todas esas pastillas." P4HTE1F22

Para las mujeres el tratamiento es un reto que enfrentan con fortaleza, toleran los efectos adversos de los medicamentos y soportan con perspectiva positiva los cambios en su vida cotidiana. En medio de un panorama complicado son autónomas en la toma de decisiones para el cuidado de su salud. Paralelo a la noticia, la indecisión de comunicar o no su situación y someterse al tratamiento, aparecen otras inquietudes como, quién contagió a quién y saber algo más sobre el VIH/SIDA, como se describe:

¿Quién contagio a quién? Desde el momento de la noticia, las mujeres relatan sentir dudas y desconfianza hacia sus parejas actuales o las anteriores. Por ello, reflexionan y toman la decisión de hablar sobre el contagio con el VIH, quieren saber cómo ocurrió, así dicen: “(...) con el papá de mi hija, fue difícil, nos echábamos la culpa el uno al otro." IBE1HSBF14. También, desean saber más sobre la enfermedad, por eso buscan información.

Buscando información sobre el VIH. Aunque la mayoría conocía algo sobre el tema, por su formación básica o experiencias de otras personas con la enfermedad, en general relataron que no tenían claridad sobre lo que significaba ser portadora del VIH y tener SIDA. Expresaron:

“(...) Cuando yo vivía con mi mamá, en ese barrio murió un muchacho y dijeron que murió de SIDA... yo siempre asociaba VIH con algo malo, como de mala conducta, como de las mujeres y los hombres promiscuos." P4HTE1F6. Por esto, uno de las necesidades de las participantes fue buscar información sobre la enfermedad, obteniéndola de la enfermera, personal médico e internet.

Además, en el difícil transitar de la gestante por el camino de convivir con VIH, el tiempo termina por convertirse en su aliado. Así, aparece la siguiente subcategoría.

Con el tiempo. El VIH, como proceso de vida, llevó a las mujeres a reflexionar y reinterpretar la vida y el sentido de la misma; analizar su relación con el equipo de salud y a pensar sobre su papel como mujer y madre. En el corto tiempo de haber recibido la noticia, sus relatos se resignifican, sienten estar viviendo una etapa distinta y positiva con su hijo e inician un proceso de asumir una nueva condición de vida. Sienten que aprendieron sobre la enfermedad, acompañan y ejercen el rol de cuidador de sus compañeros sentimentales y de su hijo.

“(...) es como tener otra oportunidad, al final uno se resigna, uno dice: pues yo no me voy a echar ni a morir, ni me voy a acostar en una cama y no voy a levantarme, no voy a comer, no voy a hacer nada ;No! lo veo como otra oportunidad." IBEIHSBF5

Con el tiempo y motivadas por una nueva oportunidad de vida, tener un hijo como centro de su cuidado a quien debe proteger y darlo todo por él, las hace fuertes, y las invita a vivir plenamente esa oportunidad.

\section{Proteger al hijo}

Todo por el hijo. Recibir el diagnóstico de VIH/SIDA durante la gestación es una experiencia inesperada y difícil, configurándose como prioridad el cuidado y protección del hijo por nacer, más que su propia vida. 
Esto explica por qué las mujeres experimentan un profundo sentimiento que trasciende la individualidad, y su cuidado tiene como objeto "proteger el hijo", por lo que están dispuestas a "todo".

También genera sentimientos de angustia e interrogantes sobre el bienestar del bebé; las explicaciones recibidas las relacionan con la salud del hijo, ya que todo lo positivo que conozca y le informen al respecto la fortalecen y le permiten tomar decisiones como: calmarse, no dejarlo solo y hacer lo que sea necesario para evitarle la infección. Esto dicen:

"No me voy a dejar de angustiar hasta saber que mi hijo está bien, que yo tenga la enfermedad no importa, pero mi hijo no...". IAE1HSF26

La necesidad del autocontrol las conduce a cuidarse para proteger a su hijo de contraer la infección y de quedarse solo si ella no está. La madre sabe que de su salud depende él/ella, razón por lo cual sigue las recomendaciones médicas aunque le representen sacrificios: cumplir con dietas, tomar medicamentos, aceptar el nacimiento por cesárea y no lactarlo. El cuidado con ella misma y el autocontrol son dos maneras de protegerlo porque más allá de su propia condición de salud, prima la de su hijo. En este escenario el aspecto clave es que su hijo no se infecte.

Que no se infecte su hijo fue el mayor deseo de las mujeres, lo que las mantiene preocupadas, expectantes y a la espera de resultados clínicos alentadores que cambie la incertidumbre por felicidad. Con el diagnóstico, sus mentes y sus deseos se centran en la necesidad de saber que éste no se ha infectado, por lo cual su fe en Dios se fortalece, creen en los números y en los resultados de los exámenes que les indican posibilidades de ser negativos y esperan que el esté en ese bajo porcentaje. Las comunicaciones médicas son asumidas como verdad absoluta, los resultados de los exámenes representan largas esperas, pero siempre con la esperanza de un reporte negativo que las tranquilice y las relaje. Ellas dicen:

Yo en mi embarazo sufrí porque yo pensé que de pronto [el bebé] me iba a nacer así [infectado]. ICE1HSBF11

Feliz porque él salió negativo... pero pues todo por él... [El bebé] P1HTE1F39

La posibilidad de una infección del hijo causa sentimientos de preocupación constante que expresan con llanto frecuente y las mantiene a la expectativa los resultados de los exámenes. El propio cuerpo es percibido como frágil, vulnerable, amenazado y amenazante para la propia vida y la de otros, en este caso del hijo que llevan dentro o de sus parejas ${ }^{16}$.

Los resultados se traducen en esperas interminables en medio de la zozobra, incertidumbre e intranquilidad, porque el diagnóstico de infección en el niño, implica evaluar la carga viral al mes y de los cuatro a cinco meses, en esta última ocasión acompañada de un recuento de linfocitos ${ }^{17}$, de manera que en el puerperio las preocupaciones se centran en el control de salud del niño hasta descartar la infección o iniciarle el tratamiento si se ha infectado, la frustración del sueño de ser mamá, cómo explicar al hijo que tiene VIH/ SIDA y cómo enfrentar el evento ante las personas que le rodean. A partir de esta preocupación nace un nuevo sentimiento: la culpa.

Es mi culpa. La gestante con VIH/SIDA, ve la culpabilidad desde dos aspectos: ella es quien trasmite la enfermedad al hijo y no puede lactarlo. Ella es fuente de infección para él, ya sea porque pese a conocer el evento en su pareja, ha quedado en gestación con la posibilidad de transmitirle la enfermedad al hijo, con la probabilidad de vivir momentos complicados en su salud que ella no desea o el pequeño es hospitalizado por esta causa y percibe en él/ella sufrimiento que como madre trata de confortar con su presencia permanente y expresiones de afecto; así lo expresan:

Antes de conocer a mi compañero, me enamoré y no lo juzgué, pero, saber que esperaba un niño, me sentí culpable, sentí que era culpa mía (silencio). P4HTE1F7 Ahora que mi hijo sigue hospitalizado, siento la misma culpa, pero lucho y todos los días estoy aquí, le hablo, lo beso y sé que pronto me lo voy a llevar para la casa. P4HTE1F35

Otra razón para sentirse culpable es la imposibilidad de lactarlo, lo acepta como la forma de protegerlo de contraer la infección, pero significa negarle una oportunidad para ser alimentado y de estrechar la conexión entre ellos. Esto expresan:

... jum [silencio] la verdad como culpable [sollozos] (26) [por no poder lactar la hija] P5HTE1F26

No poder amamantarlo es una expresión que genera sentimientos encontrados en las mujeres: un acto de amor que puede infectar al hijo. Es perder una oportunidad de estar más cerca de él, un momento anhelado; es parte de ser mamá, dar cariño y alimentarlo bien. Es una 
oportunidad que se desvanece y un anhelo inalcanzable, por eso lloran, se deprimen, se sienten tristes, es duro. Sobre estos sentimientos maternos, prima la protección del hijo contra el VIH/SIDA.

"No poderle dar pecho [llanto] si me dio duro... uno ve a todas las mamás con su bebés dándoles leche... eso se ve muy bonito, eso es ser mamá, además la leche materna es muy buena para los bebés, les da muchas vitaminas crecen muy fuertes. ” $\mathrm{P} 3 \mathrm{HTE} 131$

En medio de las limitaciones para lactarlo, desear que no se infecte y los sentimientos de culpa, la madre debe proteger al hijo de actitudes, sugerencias y comentarios poco alentadores, como se describe a continuación:

Defender al hijo implica para las mujeres enfrentar situaciones desmotivantes, desalentadoras y sentimientos de culpa, que aumentan su sufrimiento. Son las sugerencias de allegados y de profesionales de la salud sobre el bienestar y la vida de su hijo: darlo en adopción o interrumpir la gestación con el argumento de ser un hijo enfermo e infectado. Su actitud es en defensa del hijo, razón por lo cual no aceptan opciones diferentes al de darle vida a ese ser y ser madres: "Un médico me decía que era mejor abortar por la posibilidad de que mi hijo ya estuviera infectado... con tanta insistencia, que creo que me ayudó a que me sintiera más culpable (silencio...llanto)." P4HTE1F28

Estos comentarios son una razón para la inasistencia de las mujeres a los controles prenatales, al convertirse en ambientes hostiles y agresivos contra sus hijos, situaciones tormentosas y poco amigables.

\section{Confiar en alguien algo ayuda}

La experiencia de vivir con VIH y estar en embarazo también reclama ayuda. Por ejemplo, el apoyo del compañero y la familia son fuentes primarias del soporte emocional y material; son con quienes contaron en momentos difíciles, son puntos de apoyo para reducir el estigma y la discriminación y soporte en el diagnóstico y la noticia.

Pero más allá del entorno familiar, el apoyo del equipo de salud y en especial de la enfermera contribuye a confrontar las diversas situaciones vividas en la cotidianidad y en el ambiente hospitalario, sus explicaciones y palabras de aliento la hicieron sentir bien: “(...) cuando ella [enfermera del programa]... me empezó a explicar un poco más y empezó a preguntarme como estaba, pues yo me sentí bien, me gustaba hablar con ella." IBE1HSBF21. Fueron momentos agradables de comunicación en sus vidas, se sintieron apoyadas cuando los profesionales mostraron preocupación e interés por la situación y por ellas como personas. Es decir, cuando intentaron ponerse en el lugar del otro y comprender cómo se siente y piensa con respecto a la enfermedad y a lo que se dice respecto a ella; en consecuencia, se requiere de un profesional cordial y atento a las necesidades físicas, emocionales, espirituales y sociales de las gestantes que viven con VIH y del trabajo en red institucional con sentido humano.

Otra fuente de apoyo es la ayuda espiritual representada en Dios y la fe en Él que les genera confianza, fuerza y esperanza; sentirse acompañada y no derrumbarse. Como dice: "(...) me refugié mucho, primero que todo en Dios... que me diera fuerza espiritual... de que estuviera al lado mío, no me dejara sola." ICE1HSBF70. Dios es el ser que las acoge y las sostiene. Se aferran a grupos de oración, leen la Biblia y sus creencias son más fuertes; así Dios es su aliado para encontrarle sentido a la vida.

Otra forma de apoyo es el deseado de otras mujeres que viven situaciones similares, ante la necesidad de sentirse acompañadas y obtener herramientas para enfrentar su nueva condición de vida que se ve afectada por el estigma, la discriminación y el rechazo. Consideran que, compartir sus propias experiencias y conocer las de otras, les generaría confianza y crecimiento personal.

“(...) me hubiera gustado y me gustaría conversar con otras personas que hayan pasado por esta situación y me contaran como vivieron todo esto, como se cuidaron y como cuidaron a sus hijos, qué hicieron para que no les diera otra enfermedad...". IAE1HSF 31

Compartir sus experiencias con otras mujeres contribuye a responder a dudas, vacíos e inquietudes que ellas viven y necesitan corroborar que otros también lo sienten; conocimientos que les ayuda en el cuidado, a estar tranquilas y no sentirse solas en una vivencia difícil.

\section{DISCUSIÓN}

Recibir un diagnóstico de VIH durante la gestación es un evento complejo que puede implicar irrupción de la vida de las mujeres y conducirlas a pensar en la posibilidad de morir, generando desestructuración del proyecto de vida. Asimismo, para las gestantes con VIH/SIDA, el cuerpo se percibe como amenazante para sí y para sus hijos por nacer; reforzándose las imágenes del cuerpo dañado en el contexto simbólico del cuerpo 
para la procreación por la posibilidad de la trasmisión vertical del virus ${ }^{18}$.

Además, en el contexto de la demarcación de los roles de género en la sociedad occidental contemporánea, no es de extrañar que para las mujeres que cursan su gestación con diagnóstico de VIH/SIDA, el centro de sus experiencias se ubique en el punto del cuerpo amenazante para su hijo por nacer. Esto es el centro y desde donde es posible comprender el fenómeno abordado: el cuerpo, que da la vida, se convierte a la vez en uno extraño, un vehículo para la infección del hijo y que amenaza lo que más se quiere. Alrededor de esto, aparecen sentimientos de culpa, dolor y miedo; la resignación ante la falta de respuestas del fatalismo que implica la infección, y la aceptación de imposiciones como el tratamiento retroviral, la cesárea y la imposibilidad de la lactancia. Pero sobre todo, el desarrollo de prácticas de cuidado de vida, no para el bienestar de sí misma, sino para proteger su hijo.

Otro aspecto clave en la etapa de diagnóstico, son las crisis de las gestantes asociadas al escaso acompañamiento para afrontar la noticia del diagnóstico, en que además influye, el tipo y la forma con que el personal de salud brinda información; y la deficiencia en la toma de acciones preventivas para evitar el efecto físico, emocional, espiritual y social que implica ser portador de $\mathrm{VIH}^{19}$.

Así para las gestantes, ser notificadas que viven con el VIH significa la relación de varios aspectos como la carga emocional por una enfermedad estigmatizada y el peso del entorno social que se evidencia en las relaciones con los profesionales de la salud, pareja sentimental, familia y sociedad. De hecho, exige la construcción de un nuevo orden de las cosas, una nueva cotidianidad significativa ${ }^{20}$.

El impacto inicial al recibir la noticia de ser portadoras del VIH se manifiesta con llanto y silencios prolongados, ante el temor de imaginar una "experiencia dolorosa y el natural miedo a lo desconocido", que contempla una alta probabilidad de muerte ${ }^{21}$ siempre presente y que las llena de temores y angustias. Se suma a lo anterior, preguntas como ¿Por qué Yo? ¿Por qué me pasan estas cosas?, interrogantes que las invita a enfrentarse con sus "propias historias y relaciones con otros" 20.

La noticia de la seropositividad también supone el establecimiento de la prioridad para las mujeres: su hijo. Biagini et al. ${ }^{16}$ encontraron que las estrategias en salud tendientes a prevenir la transmisión vertical del VIH/ SIDA acentúan el discurso que impone a las mujeres sobre el seguimiento del tratamiento "a favor del bebé", reforzando la enorme culpabilidad, incertidumbre y angustia que su situación les provoca y enmascarando el padecimiento y sus propias necesidades, tanto en su salud física como mental. Esto se relaciona con la predisposición de las gestantes a realizar el tratamiento indicado, más por su hijo y para "estar bien" para sus hijos ${ }^{22}$.

Al impacto de la noticia, se suma la preocupación por darla a conocer a sus allegados, pues media la discriminación social que sufren las personas que viven con $\mathrm{VIH}^{19}$. La discriminación, entendida como estereotipos, reacciones y expectativas, orientadas hacia el agente de una acción particular ${ }^{15}$, es una acción promovida por el estigma cuando "En la ausencia de una justificación objetiva se realiza una distinción hacia una persona por pertenecer o por percibirse que pertenece a un grupo particular,'23. En el contexto colombiano, investigadoras como Pinilla ${ }^{24}$ y Arrivillaga et al. ${ }^{25}$ han descrito que para las mujeres, la experiencia de vivir con el VIH/SIDA, significa confrontar de manera permanente sus vidas frente al estigma que genera la enfermedad. El estigma y la discriminación puede llevar a que las mujeres tiendan a aislarse, sientan miedo de enfrentarse a la sociedad y sean susceptibles a otra serie de problemas, como la pérdida del trabajo y como consecuencia llegar a depender económicamente de sus compañeros, esposos o familiares ${ }^{26}$.

Con respecto al producto de la gestación, la posibilidad de infección del hijo es la causa de mayor preocupación de las mujeres durante la gestación y el puerperio, manteniéndolas a la expectativa de los resultados de los exámenes, que se traducen en esperas interminables en medio de la zozobra, incertidumbre e intranquilidad ya que el diagnóstico de infección en el niño implica evaluar la carga viral al mes y de los cuatro a cinco meses de nacido ${ }^{17}$.

La protección del hijo es confrontar a la mujer con el ser madre y evitar contagiarlo, mediante estrategias agresivas como evitar la lactancia materna, ocasionando la ruptura de la imagen y el mandato maternal, según la cultura en que están inmersas. Así, la protección del hijo para no contagiarlo es un proceso reflexivo que se produce con el paso del tiempo y la percepción de que los niños son "inocentes" 27 .

Finalmente, los relatos de las participantes son llamados al equipo de salud y la sociedad para encontrar apoyo social durante esta vivencia. El apoyo social tiene consecuencias en la vivencia del embarazo y en la re- 
significación y reelaboración hacia un nuevo sentido de la experiencia de convivir con la enfermedad ${ }^{28}$. La familia, si bien en algunos casos es fuente de discriminación, su participación en el proceso de apoyo emocional fue significativa para que las participantes de este estudio empezaran a reconocer su nueva condición de vida. Así, el apoyo social es considerado soporte para reducir el estigma y la discriminación ${ }^{29}$.

Así mismo, el soporte recibido de algunos médicos y enfermeras fue significativo cuando se preocuparon por el bienestar de ellas y sus hijos en gestación, evidenciando la necesidad de profesionales cordiales $\mathrm{y}$ atentos a las demandas físicas, emocionales, sociales $\mathrm{y}$ espirituales de las mujeres viviendo con $\mathrm{VIH}^{26}$; justificando el requerimiento de capacitación continua y permanente de profesionales de salud en Colombia, para trascender en el cuidado los aspectos meramente instrumentales. Al respecto, Arrivillaga ${ }^{30}$ recomienda rediseñar los programas de atención, y revisar la formación y experiencia de los profesionales de la salud que hacen parte de estos procesos. Para las mujeres gestantes que viven con VIH, su hijo es la prioridad, de manera que el apoyo institucional y profesional en salud debe fortalecer la relación madre-hijo, la continuidad del embarazo, reforzar sus redes de apoyo durante la gestación, el parto y posparto ${ }^{31}$. El estudio de Relf et al. ${ }^{32}$ plantea que además de las capacidades y destrezas de los enfermeros para cuidar físicamente personas con VIH/SIDA, requieren competencias psicosociales, espirituales y éticas que les ayude a aceptar el diagnóstico positivamente, apoyarlos espiritualmente, tener en cuenta la cultura (creencias, valores, estilos de vida, entre otros) en un plan holístico de cuidado dentro de estándares basados en evidencia, así como apoyarlos para la aceptación de su estatus de seropositividad y educar a las comunidades para reducir el estigma hacia el VIH/SIDA y a las personas para enfrentar las consecuencias del mismo.

Dentro de las demandas de apoyo social está el apoyo deseado proveniente de mujeres en su misma condición que les permite el crecimiento en una experiencia social más que personal ${ }^{19}$, donde aprenden sobre el VIH y el tratamiento, desarrollan habilidades para el control de los efectos adversos y la ingesta de los medicamentos; cuentan con espacios para desahogarse y estabilizarse emocionalmente y obtener asesoría para el cuidado de sus hijos ${ }^{30}$.

Así, se explica cómo Vivir con VIH/SIDA en la gestación es una experiencia por la protección del hijo, que relacionan tres aspectos significativos: la inesperada noticia del diagnóstico que no solo afecta su salud sino la de su hijo por nacer, en consecuencia la necesidad de proteger a su hijo de la enfermedad y la consecución de apoyos para enfrentar esta problemática.

Por lo descrito, los resultados del estudio son coherentes con otros que defienden la necesidad de comprender la gestación que cursa con un diagnóstico de VIH/SIDA como un fenómeno complejo, que excede los límites de lo biológico y los sistemas de salud; de manera que avanzar en estrategias innovadoras en la formación del personal de salud para el acompañamiento, orientación, conformación de grupos de apoyo y soporte de las gestantes que viven esta condición, es prioritario.

Este estudio tiene como limitaciones de los resultados, la imposibilidad de generalización más allá de la población de estudio o a poblaciones con características y en un contexto similar al del estudio.

\section{CONSIDERACIONES ÉTICAS}

El proyecto fue aprobado por los Comités de Ética en investigación clínica de las Empresas Sociales del Estado de tercer nivel de la ciudad de Bogotá (Actas AS-1388/13 y CIEIC- 41-13 respectivamente) donde se realizó el estudio y por el Comité de Ética de la Facultad de Enfermería-Universidad Nacional de Colombia (Acta 1 de abril de 2013. UGI-088-2013). Fue un estudio sin riesgo según la Resolución 008430 de 1993 del Ministerio de Salud de Colombia. Se preservó la privacidad y confidencialidad de las participantes y se utilizó una forma escrita de consentimiento informado para todas las participantes, previa comprensión del objetivo y alcances del estudio.

\section{CONFLICTO DE INTERÉS}

Las autoras declaran que no existen conflictos de interés.

\section{AGRADECIMIENTOS}

Proyecto docente financiado por la Universidad Nacional de Colombia. Facultad de Enfermería. Cód. Hermes 17356. Las autoras desean expresar sus agradecimientos a las Instituciones y mujeres participantes.

\section{REFERENCIAS}

1. Programa Conjunto de Naciones Unidas sobre el VIH/SIDA. El sida en cifras 2015. Informe ONUSIDA 2015; 3- 11.

2. Programa Conjunto de Naciones Unidas sobre el VIH/SIDA. Estadísticas Globales-Hoja Informativa 
2015. ONUSIDA 2015; 1-8.

3. Colombia. Ministerio de Salud y Protección social. Plan estratégico para la eliminación de la transmisión materno-infantil del VIH y la Sífilis Congénita 2011-2015. Bogotá. Diciembre, 2010.

4. Colombia. Ministerio de Salud y Protección social. Boletín epidemiológico, situación del VIH/Sida Colombia. Boletín Epidemiológico VIH/Sida, Colombia. Octubre 2013; 1-|19.

5. Díaz LA, Serrano NC. Oportunidades de investigación en preeclampsia, desde la perspectiva de prevención primaria: Un artículo de reflexión. Rev Colomb Obstet Ginecol. 2008; 59(3): 206-215.

6. Vecino-Ortiz AI. Determinants of demand for antenatal care in Colombia. Health Policy. 2008; 86(2-3): 363-372. DOI: 10.1016/j. healthpol.2007.12.002.

7. Galeano M. Diseño de proyectos en la investigación cualitativa. Medellín: Fondo Editorial Universidad EAFIT, 2004.

8. Husserl E. Experiencia y juicio. México: UNAM, 1980.

9. Gomes Terra G, da Silva LC, Camponogara S, dos Santos E, Jatobá de Souza AI, Lorenzini Erdmann AL. Na trilha da fenomenologia: um caminho para a pesquisa em enfermagem. Texto Contexto Enfermagen. 2006; 15(4): 672-678. DOI: http:// dx.doi.org/10.1590/S0104-07072006000400016.

10. Wojnar DM, Swanson KM. Phenomenology: an exploration. J Holist Nurs. 2007; 25(3): 172-180. DOI: $10.1177 / 0898010106295172$.

11. Sandoval C. Investigación cualitativa: programa de especialización en teoría, métodos y técnicas de investigación social. Bogotá: ICFES, 1997.

12. Bertaux D. Los relatos de vida. Perspectiva etnosociológica. Barcelona: Bellaterra, 2005.

13. Bautista NP. Proceso de la investigación cualitativa. Epistemología, metodología y aplicaciones. Bogotá: Manual Moderno, 2011.

14. Creswell J. Qualitative inquiry and research design. Choosing among five approaches. Nebraska: SAGE Publications Inc, 2007.

15. Castillo E, Vásquez ML. El rigor metodológico en la investigación cualitativa. Colomb Médica. 2003; 34(3): 164-167.

16. Biagini G, Grigaitis L, Giri B. Embarazo y VIH/ SIDA: vivencias del proceso salud-enfermedadatención. Buenos Aires: Editorial Ubatec S.A., 2008.

17. García R, Prieto F, Arenas C, Rincón J, Caicedo S, Rey G. Reducción de la transmisión madre hijo del VIH en Colombia: dos años de experiencia nacional, 2003-2005. Biomédica. 2005; 25(4): 547-564.
18. Grimberg M. Narrativas del cuerpo: experiencia cotidiana y género en personas que viven con VIH. Cuadern Antropol Social. 2003; 17: 79-99.

19. Bravo M, Dides C, Pascal R. Mujeres viviendo con VIH/SIDA: diagnóstico sobre ética y derechos sexuales y reproductivos. Santiago de Chile: Edición Vivo Positivo, 2003.

20. García G. Cuerpo y narrativa: una aproximación etnográfica al proceso de atención del embarazo, parto y puerperio de mujeres viviendo con VIH en la ciudad de Buenos Aires. Horiz Antropol. 2009; 15(32): 247-272. DOI: http://dx.doi.org/10.1590/ S0104-71832009000200011.

21. Bustamante M. Viviendo con VIH, muriendo con SIDA. [Tesis de maestría]. Quito: FLACSO sede Ecuador; 2001.

22. Arrivillaga M, Ross M, Useche B, Alzate ML, Correa D. Social position, gender role, and treatment adherence among Colombian women living with HIV/AIDS: social determinants of health approach. Rev Panam Salud Pública. 2009; 26: 502-510.

23. Parker R, Maluwa M. Estigma y discriminación por VIH-SIDA: un marco conceptual e implicaciones para la acción. Ciudad de Guatemala: ONUSIDA, 2011.

24. Pinilla M. Mujeres viviendo con VIH: más allá de una historia. [Tesis de Maestría]. Bogotá: Universidad Nacional de Colombia sede Bogotá; 2009.

25. Arrivillaga M, Correa D, Varela M, Holguín L, Tovar J. Variables psicológicas en mujeres diagnosticadas con VIH/SIDA: un estudio correlacional. Universitas Psychol. 2006; 5(3): 659-667.

26. Leite Araújo MA, Bastos da Silveira C, Bastos da Silveira C, Paes de Melo S. Vivências de gestantes e puérperas com o diagnóstico do HIV. Rev Bras Enfermagem. 2008; 61(5): 589-594. DOI: http:// dx.doi.org/10.1590/S0034-71672008000500010.

27. Carrasco-Aldunanete P, Araya-Gutiérrez A, LoayzaGodoy C, Ferrer Lagunas L, Trujillo-Guarda C, Fernández Sarmiento $\mathrm{A}$, et al. Cómo entender la experiencia de personas que viven con VIH: implicaciones para la clínica y la investigación. Aquichán. 2013;13(3): 387-395.

28. Defey D. El trabajo psicológico y social con mujeres embarazadas y sus familias en los centros de salud. Montevideo: PNUD, 2009.

29. Kisakye P, Akena WO, Kaye DK. Pregnancy decisions among HIV-positive pregnant women in Mulago Hospital, Uganda. Cult Health Sex. 2010; 12(4): 445-454.DOI: 10.1080/13691051003628922.

30. Arrivillaga M. Determinación social de la adherencia terapéutica. Alternativa conceptual y metodológica 
aplicada al caso de mujeres viviendo con VIH/ SIDA. [Tesis de doctorado]. Univerisdad Nacional de Colombia: Bogotá; 2010.

31. Sofolahan YA, Airhihenbuwa CO. Childbearing Decision Making: A Qualitative Study of Women Living with HIV/AIDS in Southwest Nigeria. AIDS Research and Treatment. 2012; 2012: 1-8. DOI $10.1155 / 2012 / 478065$.

32. Relf M, Mekwa J, Chasokela C, Nhlengethwa W, Letsie E, Mtengezo J, et al. Essential Nursing Competencies Related to HIV and AIDS. J Assoc Nurses AIDS Care. 2011; 22(1 Suppl): 5-40. DOI: 10.1016/j.jana.2010.07.007. 